\title{
reviews
}

\section{Reading about ... self-help books on bereavement}

Surviving the death of one we love is something most of us will experience at some time in our lives and yet it is something for which we tend to feel wholly unprepared. The combination of longevity and nuclear family structures means that those of us in the technologically developed world are not often exposed to death, making bereavement unfamiliar. In addition, the taboo nature of death and the private nature of modern grief mean that death and our reactions to it are not openly discussed and remain mysterious. So it is perhaps no wonder that as clinicians we may want to be armed with resources to recommend to patients who suffer bereavement.

As with many areas pertaining to mental health and well-being, an abundance of texts and websites providing personal accounts and advice is available. A Google search using the terms 'self-help' and 'bereavement' yields over half a million hits! It is not possible to systematically review such a wealth of material, but in putting forward the following ideas I am informed by my own experience in working with older people after bereavement and that of colleagues from a range of settings.

The needs of patients or relatives will vary greatly, from wanting basic practica information, a desire to know what to expect, a need for reassurance that their own response is 'normal', and possibly to a wish to know how to help themselves or their relatives to adapt and adjust to life without the deceased person. Material addressing all these areas is available both on the internet and in book/leaflet form.

Practical information about what to do after a death is not the main subject of this article. Suffice it to say that Directgov, 'the official government website for citizens,' which aims to give easy access to information about public services, is the place to go for sound information about all immediate practical aspects, from registering the death, to arranging the funeral, to understanding wills and probate (www.direct.gov.uk/en/ Governmentcitizensandrights/Death / index.htm). The website also has links to the major organisations that offer support to those who are bereaved.

Brief, well-organised, generally highquality material about common emotional reactions to bereavement is widely available and most readily accessed through the internet with the BBC (www.bbc.co.uk/relationships/copingwith-grief/), CRUSE Bereavement Care (www.crusebereavementcare.org.uk/ index.html) and the Royal College of
Psychiatrists (www.rcpsych.ac.uk/

mentalhealthinformation /

mentalhealthproblems/bereavement/ bereavement.aspx) being three of the most comprehensive websites. The materials on the CRUSE and College sites are also available as leaflets.

These websites address emotional responses of adults and children, provide information about various types of loss (e.g. sudden deaths, deaths by suicide, stillbirths), make suggestions about what can help and provide links to other websites including those catering for people with particular types of bereavement (e.g. Compassionate Friends, the organisation for parents bereaved of a child). For the most part, the websites differ by style rather than content, though it may be the case that the College website still gives prominence to the stage/phase notion of adaptation to bereavement, whereas the other two sites promote the more post-modern, and indeed research-supported, idea of there being many different ways to adapt.

CRUSE has two attractive, simply constructed pages with basic information about emotional responses, called 'About Bereavement' and 'What Can Help'. These use quotations from bereaved people such as: 'I wanted people to say they knew what had happened, not avoid it or pretend they didn't know'. These make their point effectively without being proselytising.

Rather surprisingly, none of them pay much attention to issues of faith or religion following death and only the College's website seems to provide information tailored for people with intellectual disabilities and to provide some translations of information.

Aside from brief leaflets and website information, many people who have been bereaved seem to be drawn towards reading autobiographical accounts. These personal stories have the power to reassure by helping a person to realise that they are not alone; that others have experienced the same sense of devastation, yet they survive. Such accounts may be seen as especially valid precisely because they have been written by 'ordinary people' rather than professionals.

There are many such personal accounts, with some of the most moving being by those who are experienced and accomplished writers. Virginia Ironside, columnist for the Independent and The Oldie, writes about the impact of the death of her father in 'You'll Get Over It': The Rage Of Bereavement. ${ }^{1}$ The book is known for its brutal honesty and dismissal of sentimentality and platitudes. One of the aspects that seems to strike a chord with readers is the acknowledgement that actually you do not 'get over' the loss of someone whom you have loved very dearly.

The American writer Joan Didion's My Year of Magical Thinking ${ }^{2}$ is an account of the 12-month period following the death of her husband of over 40 years from a heart attack. She writes from an explicit need to gain selfunderstanding and she captures beautifully that odd quality of irrational thinking we may experience after a death: '. . . the primitive dread that had been awakened by the autopsy question ... How could he come back if they took his organs, how could he come back if he had no shoes?'

As a final example, Dannie Abse's The Presence $^{3}$ gives memoirs from the year following the death of his wife, Joan Abse, who was killed in a car crash at the age of 78 years. His qualities as a doctor and a poet shine through as he gives an intimate and heart wrenching account of living with the consequences of a sudden and traumatic bereavement, illustrated here with a few lines from his poem on the final page of the book.

Last night, lying in bed I remembered how, pensioners both, before sleep, winter come, your warmfoot suddenly would console my cold one.

Finally, to turn to self-help books. In an era which problematises grief, it is not surprising to find that there are self-help books that provide tips and advice on 'self-therapy'. These have been written both by people who want to draw on their own direct experience of bereavement to help others and by professionals from a variety of backgrounds. The former feel far less satisfactory than autobiographical accounts. A journal or memoir can be unashamedly biased and idiosyncratic and benefits from being written while a person is in the thick of grief, whereas advice is better provided from a broader perspective and a cooler emotional position. I touch below on three recent books by professionals.

I turned to Sue Morris's Overcoming Grief: A Self-Help Guide using Cognitive Behavioural Techniques, ${ }^{4}$ with some ambivalence generated by the recent prominence of cognitive-behavioural therapy (CBT) to the possible exclusion of other therapeutic approaches. However, the material is couched within a broader understanding of grief and does place emphasis on the unique nature of each person's grief. The book has a direct style of writing and is generally focused on problem-solving with talk of 'overcoming the hold' of grief and 'taking charge' again. Some of the best material is perhaps in Chapter 4 'Regaining control', with 